\title{
A POTÊNCIA DAS IMAGENS NOS PROCESSOS DE CURRÍCULOSFORMAÇÕES: RIZOMA, AFECÇÕES AS REDES DIGITAIS DE CONVERSAÇÕES E WHATSAPP E FACEBOOK
}

\author{
THE POWER OF IMAGES IN THE CURRICULUMFORMATIONS \\ PROCESSES: RHIZOME, AFFECTIONS TO DIGITAL CONVERSATIONS \\ NETWORKS AND WHATSAPP AND FACEBOOK
}

\author{
Julio César da Silva de Alvarenga ${ }^{1}$
}

\begin{abstract}
Resumo: Tal pesquisa busca nos estudos dos currículos problematizar acerca da potência da imagem-movimento capturadas (DELEUZE, 2018a), como uma composição potente nos processos de currículosformações (FERRAÇO; GOMES, 2013) da escola municipal Lacerda de Aguiar da rede municipal de ensino de Piúma-ES, entre alunos do $7^{\circ}$ ao $9^{\circ}$ ano do ensino fundamental, tendo como um dos intercessores deste processo formativo o uso do aplicativo WhatsApp. Tomando por base os estudos deleuzianos acerca do confronto entre o materialismo com o idealismo, onde um buscava reconstituir a ordem da consciência com movimentos materiais e o outro com puras imagens na consciência (DELEUZE, 2018a), buscamos principalmente no conceito de imagem, pensar nas composições rizomáticas possíveis, alinhando para tanto a ideia de capturar imagens do cotidiano nos processos currículosformações.
\end{abstract}

Palavras-chave: Deleuze; imagens; currículo.

\begin{abstract}
Such research seeks in the studies of the curricula to problematize about the power of the captured image-movement (DELEUZE, 2018a), as a potent composition in the curriculumformations processes (FERRAÇO; GOMES, 2013) of the municipal school Lacerda de Aguiar of the municipal school system of Piúma-ES, among students from the 7th to the 9th grade of elementary school, using the WhatsApp application as one of the intercessors of this formations process. Based on Deleuzian studies on the confrontation between materialism and idealism, where one sought to reconstitute the order of consciousness with material movements and the other with pure images in consciousness (DELEUZE, 2018a), we seek mainly in the concept of image, thinking about possible rhizomatic compositions, aligning the idea of capturing everyday images in the curriculumformations processes.
\end{abstract}

Keywords: Deleuze; images; curriculum.

No atual cenário, as Tecnologias da Informação e Comunicação (TICs) estão cada vez mais arraigadas na ação e reflexão humana. $\mathrm{O}$ modo como as pessoas estão fazendo uso de tais tecnologias, vem passando por um rápido processo de naturalização, e já se encontram incorporadas nas práticas cotidianas, sem que se perceba o avanço do uso das TICs no dia a dia (CORREAA, 2003). Dessa forma, o uso das hipermídias no ciberespaço é um colaborador para a criação de condições para os processos de mudanças que podem ocorrer na sociedade, o que conduz à noção atual de estarmos vivendo na sociedade da informação, construindo novos coletivos de seres humanos e mídia informática (LÉVY, 2010) e que, fazem parte dos cotidianos das escolas.

A pesquisa objetiva problematizar a potência das redes sociais, especificamente, no uso do aplicativo WhatsApp na composição dos currículosformações da rede municipal de Piúma. Para tanto, pretende-se capturar as imagens-movimento, emergidas das redes sociais dos que praticam

\footnotetext{
${ }^{1}$ Doutorando em Educação pela Universidade Federal do Espírito Santo. Membro do Grupo de Pesquisa Currículos, culturas, cotidianos e redes de conhecimentos. E-mail: jcsalvarenga@gmail.com.
} 
os cotidianos escolares, como sendo processos rizomáticos de tessitura curricular e problematizar como as relações de afecções se dão a partir de algumas cenas postadas pelos alunos.

Com a pandemia do COVID- $19^{2}$ ferramentas de comunicação instantânea móvel tem se tornado aliadas ainda maiores da educação, ainda que nesse momento e da forma como estejam sendo inseridas, a comunidade acadêmica esteja questionando seu uso, sem objetivos claros e estudos mais aprofundados. Atualmente existem diversas ferramentas disponíveis para acesso público, tais como o Google Talk, também conhecido por Hangout, Skype, Viber, Telegram e Facebook Messenger. Entretanto, uma das ferramentas mais utilizadas atualmente é o WhatsApp. Esse nome, WhatsApp, tem origem na tradução em inglês do termo "What's up?"- que significa $o$ que se passa ou ainda, quais as novidades (ALMEIDA, 2015). Um dos grandes diferenciais do WhatsApp está na possibilidade de envio e recebimento de variadas mídias como imagem, áudio, vídeo e emojis (figuras prontas que demonstram expressões e sentimentos), é possível ainda a criação de grupos de conversa, transmissão de diálogos, realização de chamadas de áudio e também de vídeo, entre outras opções, facilitando assim a comunicação de forma exponencial entre os professores e alunos, principalmente nesse momento em que as autoridades de saúde pública solicitam o isolamento social como medida para minimizar o contágio pelo COVID-19, e as aulas presenciais em praticamente todo o país e diversos países do mundo, estão suspensas. ${ }^{3}$

As modificações nessa sociedade, causadas pelas Tecnologias da Informação e Comunicação, são profundas e transformam a maneira que pensamos (LÉVY, 2010), ou seja, “[...] transformam o modo como nós dispomos, compreendemos e representamos o tempo e o espaço a nossa volta" (KENSKI, 2004, p. 31). Nesse cenário, um dos grandes desafios para os docentes é ajudar a tornar a informação significativa, a escolher as informações verdadeiramente importantes entre tantas possibilidades, a compreendê-las de forma cada vez mais abrangente e profunda e a torná-las parte do nosso referencial.

Faz-se uso da perspectiva teórico-metodológica da pesquisa com os cotidianos ao explorar Alves $(2008 ; 2011)$ no que concerne ao contexto das práticasteoriaspráticas de produção e usos de mídias, Ferraço (2016) ao apostar na potência dos currículos como processos que se dão a partir das experiências com os cotidianos e os estudos dos currículos e Carvalho (2014), Carvalho e Roseiro (2017) e Deleuze (2018a) para pensar na imagem-movimento, objeto central do nosso estudo. Utilizamos os estudos de Deleuze e Guatarri (2017) que contribuem para problematizar os processos de tessitura curricular como uma ação rizomática, entendendo assim também, sua importância na possível utilização das TICs, em especial a ferramenta WhatsApp e da imagemmovimento nos processos de formação docente/discente.

Estudos de Alves (2008) e Garcia e Alves (2012) colaboram para problematizar os contextos da formação docente.

Nesta perspectiva, as redes sociais são pensadas como “[...] linguagem a ser desenvolvida nas escolas por docentes e discentes, em espaçostempos para troca de conhecimentos e significações de todo o tipo" (GARCIA; ALVES, 2012, p. 504-505). Portanto, interessa-nos problematizar como que as múltiplas interações realizadas no uso do WhatsApp possibilitam processos potentes de tessitura dos currículosformações.

Apoiamo-nos em Lévy $(2010 ; 2011 ; 2018)$ e Moran (2017) que colaboram para pensar acerca das relações entre tecnologia e educação, e, fazemos uso dos estudos deleuzianos

\footnotetext{
${ }^{2}$ Coronavírus é uma família de vírus que causam infecções respiratórias. O novo agente do coronavírus foi descoberto em 31/12/19 após casos registrados na China. Provoca a doença chamada de coronavírus (COVID-19). No entanto, foi em 1965 que o vírus foi descrito como coronavírus, em decorrência do perfil na microscopia, parecendo uma coroa. Disponível em: https://coronavirus.saude.gov.br/sobre-a-doenca\#o-que-e-covid.

${ }^{3}$ Este artigo foi escrito entre 10/02/2020 e 02/05/2020, momento em que a pandemia do COVID-19 se tornava uma realidade mundial.
} 
para pensar nas composições rizomáticas enquanto processos de produção de currículosformações entendendo que:

Para além da ideia de currículos e de processos de formação de professores
reduzidos a prescrições, e dos docentes como técnicos, burocratas e
reprodutores do modelo social vigente, quando discutimos as políticas de
currículo e de formação de educadores juntando as palavras - os
currículosformações-, passamos a compreende-las em seus enredamentos da
vida cotidiana, como fios das práticaspolíticas desses educadores que só
fazem sentido se pensados juntos (FERRAÇO; GOMES, 2013, p. 466).

No atual cenário global, as Tecnologias da Informação e Comunicação (TICs) estão cada vez mais arraigadas na ação e reflexão humana. O modo como as pessoas estão fazendo uso de tais tecnologias vem passando por um rápido processo de naturalização, e já que estas se encontram incorporadas nas práticas cotidianas, já é quase imperceptível identificar o avanço do uso das TICs no dia a dia (CORRÊA, 2003). Dessa forma, o uso das hipermídias no ciberespaço é um colaborador para a criação de condições para os processos de mudanças que podem ocorrer na sociedade, o que conduz à noção atual de estarmos vivendo na sociedade da informação, construindo novos coletivos de seres humanos e mídia informática (LÉVY, 2010) e que, fazem parte dos cotidianos das escolas.

Tecidas estas considerações, essa pesquisa objetiva problematizar a potência das imagensnarrativas que emergem das redes sociais, especificamente, no uso do Facebook e do WhatsApp na composição dos currículosformações nas turmas do $7^{\circ}$ ao $9^{\circ}$ ano do ensino fundamental da Escola Municipal Lacerda de Aguiar.

Para tanto, pretende-se capturar imagens e narrativas, emergidas das redes sociais dos praticantes (CERTEAU, 2014) que compõem a vida no cotidiano escolar, como sendo processos rizomáticos de tessitura curricular e problematizar como as relações de afecções se dão a partir de cenas e narrativas postadas pelos alunos nestas redes sociais.

Fazemos uso da perspectiva teórico-metodológica da pesquisa com os cotidianos ao explorar Alves $(2008 ; 2011)$ no que concerne ao contexto das práticasteoriaspráticas de produção e "usos" de mídias, Ferraço (2016) ao apostar na potência dos currículos como processos que se dão a partir das experiências com os cotidianos, Lévy $(2010 ; 2011 ; 2018)$ e Moran (2017) como intercessores ${ }^{4}$ que sustentam os estudos sobre as tecnologias e a educação, e Deleuze $(2010 ; 2018 \mathrm{a} ; 2018$ b) para pensar o conceito de acontecimentos, linguagem, e imagem-movimento e imagem-tempo. Por fim, utiliza-se dos estudos de Deleuze \& Guattari (2017), na coletânea Mil Platôs que contribuem para problematizar os processos de tessitura curricular como uma ação rizomática.

Estudos de Alves (2008) e Garcia e Alves (2012) colaboram para problematizar os contextos da formação docente. Segundo as autoras, o processo formativo,

[...] se dá em múltiplos contextos, em diferentes momentos, num processo que tem início muito antes da entrada em uma escola e que se oficializa num curso de formação de professores e tem continuidade no decorrer da ação docente, num rico processo em que práticateoria, em articulação permanente, vão

\footnotetext{
${ }^{4}$ No pensamento deleuziano a noção de "intercessores", no plural, são quaisquer encontros que fazem com que o pensamento se movimente. De acordo com Deleuze (1992b, p. 156): “O essencial são os intercessores. A criação são os intercessores. Podem ser pessoas - para um filósofo, artistas ou cientistas; para um cientista, filósofos ou artistas - mas também coisas, plantas, até animais, como em Castañeda”.
} 
dando continuidade ao processo interminável dessa formação. (GARCIA; ALVES, 2012, p. 489-490).

Consideramos que os espaços de formação docente, pensados nesta pesquisa como um entrelaçamento de currículo e formação, ou seja, como currículosformações, se dão em múltiplos contextos, dentre os quais, inclui o contexto das práticasteorias de produção e usos de mídias. Garcia e Alves (2012, p. 504) afirmam:

Pesquisas com os cotidianos, preocupadas com as relações que os docentes estabelecem com o mundo da comunicação da televisão, em diversas gerações, ajudam a compreender os modos como as redes de conhecimentos e significações vão se articulando com esses meios para além da reprodução e da transmissão, criando tecnologias nos "usos" cotidianos de artefatos culturais.

Mas afinal o que seriam as mídias? Para Charaudeau (2006), mídias, informação e comunicação, são palavras de ordem no discurso da modernidade. Assim, uma primeira distinção se impõe se quisermos tratar desses conceitos: "informação" e "comunicação" são noções que remetem a fenômenos sociais; as mídias são um suporte organizacional que se apossa desses conceitos para integrá-las em suas diversas lógicas - econômica, tecnológica e simbólica.

Sob essa ótica, as redes sociais, são pensadas como “[...] linguagem a ser desenvolvida nas escolas por docentes e discentes, em espaçostempos para troca de conhecimentos e significações de todo o tipo" (GARCIA; ALVES, 2012, p. 504-505). Interessa, portanto, problematizar como que as múltiplas interações advindas dos cotidianos escolares manifestadas no uso do Facebook e do WhatsApp, possibilitam processos potentes de tessitura dos currículosformações.

Ressalta-se que no contexto desse estudo, mídias de informação, devem ser aqui entendidas, de maneira restrita, como o conjunto de suportes tecnológicos que têm o objetivo social de difundir as informações relativas aos acontecimentos que se produzem no mundoespaço público: imprensa, rádio, televisão, internet e com ela as redes sociais. Garcia e Alves (2012, p. 504) afirmam que:

Pesquisas com os cotidianos, preocupadas com as relações que os docentes estabelecem com o mundo da comunicação da televisão, em diversas gerações, ajudam a compreender os modos como as redes de conhecimentos e significações vão se articulando com esses meios para além da reprodução e da transmissão, criando tecnologias nos "usos" cotidianos de artefatos culturais.

É neste contexto de utilização e "usos" cotidianos, de novas e diferentes tecnologias, que professores em sua grande maioria nascidos antes de 1980 recebem como seus alunos, a nova geração de discentes, considerados nativos digitais, e é nesse cenário que Prensky (2001) afirma ser necessário um novo formato de ensino, adequado às demandas dos discentes, a era da globalização dos smartphones.

O nativo digital, aquele que nasceu nesse mundo, e o imigrante, aquele que nele chegou (PRENSKY, 2001), foram ocupando seu lugar no processo de aprendizagem contemporânea, na escola e na universidade, e além delas, desvirtuando-as de sua dimensão tradicional ao tecer redes sociais e porque não, redes de conhecimentos.

Um dos pilares dessa nova geração é a utilização fluente das TICs, sendo, portanto, atribuída aos docentes a incumbência de atualização de suas práticas pedagógicas para que possam acompanhar o desenvolvimento das novas mídias de forma que consigam promover a inserção dessas novas ferramentas digitais em suas atividades e, ao mesmo tempo, acompanhar 
a evolução dos alunos. O processo de ensinaraprender acontecem em uma interligação simbiótica ${ }^{5}$, profunda e constante entre os mundos físico e digital (MORAN, 2017).

Nos últimos anos, o cenário se transformou profundamente. O smartphone é onde tudo acontece. O tempo todo olhamos para sua tela, teclamos, pesquisamos, compartilhamos, jogamos, compramos, rimos, nos relacionamos e aprendemos. É o aparelho que carregamos para todos os lugares, nosso companheiro inseparável, a pequena tela que aumenta, que integra milhares de aplicativos e soluções antes soltas. Os assistentes pessoais dialogam com as pessoas, aprendem com elas, propõem soluções cada vez mais personalizadas e produtivas. (MORAN, 2017. p. 64).

É pensando nessa forma de ensinaraprender, supramencionada por Moran, que buscamos fundamentar nossa pesquisa em um estudo que envolva a potência das redes sociais nos processos de currículosformações: rizoma, afecções, Facebook e WhatsApp.

Neste sentido, o interesse dessa pesquisa perpassou por problematizar a potência das imagensnarrativas (in)capturadas a partir das redes sociais e as múltiplas interações realizadas no uso das redes sociais, Facebook e WhatsApp, possibilitando processos potentes de tessitura dos currículosformações.

E por que a escolha pelas redes sociais Facebook e WhatsApp? Inicialmente por serem, Facebook, WhatsApp e Instagran, ferramentas pertencentes a um mesmo grupo e com facilidades de comunicação e pesquisas. Do mesmo modo, segundo o próprio site Facebook, o WhatsApp totalizou 800 milhões de usuários, em 2015, com uma média de 1 milhão de novos usuários por dia, chegando a um volume de 30 bilhões de mensagens enviadas diariamente. Atualmente segundo o próprio aplicativo que agora pode ser acessado também por meio web, o número de usuários já passa de 2 bilhões.

O aplicativo disponibiliza diversos recursos interessantes de comunicação como o envio de texto, fotos, áudios, vídeos e de efetuar ligações (WHATSAPP, 2020), que utilizado com o devido equilíbrio, tende a se transformar em uma ferramenta pedagógica de grande valia e capaz de tornar-se um grande aliado do pesquisador na (in)captura de imagensnarrativas que são produzidas no cotidiano escolar por discentes e docentes.

Nesse cenário tão dinâmico, a escola parece parada no tempo. Está off-line em um mundo on-line. O Whatsapp é o aplicativo que expressa a febre da atualização incessante, ao vivo, em multigrupos, do fluir incessante de mensagens, vídeos, comentários. A escola parece um museu, um outro mundo, um espaço de confinamento, quadrado, com tempos marcados para cada área de conhecimento, para cada atividade, para cada avaliação. A escola parece fora do lugar em mundo conectado on-line (MORAN. 2017. p. 66).

A pesquisa vem se desenvolvendo em um momento que a escola está passando por uma reestruturação em sua gestão, e que assim descobrimos particularidades que muito contribui para a realização da pesquisa, o que contrapõe a supracitada afirmação de Moran ao comparar a escola a "um museu, um outro mundo, um espaço de confinamento, quadrado, com tempos marcados para cada área de conhecimento, para cada atividade, para cada avaliação. A escola parece fora do lugar em mundo conectado on-line", uma vez que a direção da escola desenvolve com o corpo técnico um projeto experimental de liberação dos smartphones para fins de pesquisas durante as aulas e

\footnotetext{
${ }^{5}$ Para esse estudo levaremos em consideração o conceito de interligação simbiótica como uma inter-relação de forma próxima entre as tecnologias e os atores dos cotidianos escolares.
} 
possibilitando ainda o uso dos aparelhos no intervalo do recreio, o que tem nos movido a acreditar que conseguiremos capturar inúmeros dados relevantes para a pesquisa.

Nos últimos anos, as tecnologias móveis estão cada vez mais aparelhadas para auxiliar o ensinaraprender dentrofora da sala de aula. Pensamos, a priori, que as conexões e movimentos no uso das redes sociais estão mediados por uma dimensão rizomática, em expansão o tempo todo e em articulaçãoconexão a outras redes, a outras formações, a outros currículos.

[...] o rizoma conecta um ponto qualquer com outro ponto qualquer e cada um de seus traços não remete necessariamente a traços de mesma natureza; ele põe em jogo regimes de signos muito diferentes, inclusive estados de não signos. $\mathrm{O}$ rizoma não se deixa reconduzir nem ao Uno nem ao múltiplo. Ele não é o Uno que devém dois, nem mesmo que deviria diretamente três, quatro ou cinco, etc. Ele não é um múltiplo que deriva do Uno, nem ao qual o Uno se acrescentaria $(\mathrm{n}+1)$. Ele não é feito de unidades, mas de dimensões, ou antes de direções movediças. Ele não tem começo nem fim, mas sempre um meio pelo qual ele cresce e transborda. Ele constitui multiplicidades lineares a $n$ dimensões, sem sujeito nem objeto, exibíveis num plano de consistência e do qual o Uno é sempre subtraído (n-1). Uma multiplicidade não varia suas dimensões sem mudar de natureza nela mesma e se metamorfosear (DELEUZE; GUATARRI, 2017, p. 43).

Nesta dimensão rizomática, as redes sociais na dimensão movediça se conectam a outros movimentos ${ }^{6}$ das vidas cotidianas e possibilitam produzir outras conversas, narrativas, imagens ${ }^{7}$, encontros, amizades que potencializam os currículos vividospraticados no chão das escolas.

Buscamos com a pesquisa em curso, identificar que produções curriculares emergem dessas relações que se conectam o tempo todo via redes sociais, Facebook e WhatsApp? Que conversasnarrativas escapam nestas redes e nos faz pensar em outras possibilidades de curricular e de formação docente? Que relações de afetos-amizades podem ser capturadas como uma força potente dos currículos? Que imagens-movimentos são produzidos e circulados em rede e que afetam os processos de currículosformações? Estas indagações concebidas como um movimento de violentar o pensamento nos dão pistas para inferir que, os acontecimentos cotidianos escapam o tempo todo das prescrições curriculares, das regulações e proibições no uso, por exemplo, do celular nas escolas, e são produções coletivas e negociadas de saberesfazeres docentes.

Para Deleuze o acontecimento deve ser compreendido, e apresenta o acontecimento como algo incorporal, inabalável. Sua afirmação baseia-se em Joe Bousquet, o qual elabora em sua escrita uma reflexão a respeito da ferida, do acontecimento e da linguagem. Para Deleuze, a ferida que ele - Bousquet - traz em seu corpo, é apreendida “[...] na sua verdade eterna como acontecimento puro, no entanto, e tanto mais que" (DELEUZE, 2015, p. 151). Assim o exemplo da ferida para Deleuze, tem a função de recordar o que ele já dissera a respeito dos incorporais inabaláveis e do acontecimento como incorporal. Partindo desse pressuposto, Deleuze busca robustecer o objetivo central do exemplo citado, que é demarcar o acontecimento como um efeito de superfície, um incorporal, uma "quase-causa", alguma coisa (aliquid) que acontece e

\footnotetext{
${ }^{6}[\ldots]$ O movimento remete sempre a uma mudança, migração, a uma variação sazonal. É a mesma coisa para os corpos: a queda de um corpo supõe um outro que o atrai e exprime uma mudança no todo que os compreende a ambos. [...] Mas as próprias qualidades são puras vibrações que mudam ao mesmo tempo que os pretensos elementos se movem (DELEUZE, 2018a, p. 22-23).

${ }^{7}$ É claro, a principal obra deleuziana sobre o conceito de imagem é Cinema, com seus dois volumes. De inspiração bergsoniana, ela aborda a imagem cinematográfica por dois prismas explicativos: a imagem-movimento e a imagem-tempo, as quais são, por sua vez, explicadas segundo diversas subdivisões (imagem-percepção, imagem-afecção, imagem-pulsão etc.), para assim fazer a “taxonomia” ou o "ensaio de classificação das imagens e dos signos” (2018a, p. 13-27).
} 
que, por sua vez, não se reduz nem às coisas nem às proposições, mas só pode ser apreendido no instante mesmo em que acontece.

[...] Estes efeitos não são corpos, mas, propriamente falando, 'incorporais'. Não são qualidades e propriedades físicas, mas atributos lógicos ou dialéticos. Não são coisas ou estados de coisas, mas acontecimentos. Não se pode dizer que existam, mas, antes, que subsistem ou insistem, tendo este mínimo de ser que convém ao que não é uma coisa, entidade não existente. Não são substantivos ou adjetivos, mas verbos. (DELEUZE, 2015, p. 5).

Nesta perspectiva, para capturar os afetos que emergem das relações entrelaçadasmovediças nas redes sociais e principalmente no Facebook e WhatsApp, propomos aqui, sem a presunção de criar um novo conceito, utilizarmo-nos do termo redes digitais de conversas, em referência a expressão redes de conversações que Carvalho (2009) utiliza, e Alves (2019, p. 19) readaptou para "redes de conversas":

Essas "redes de conversas" se dão nas inúmeras redes educativas que formamos com muitos outros e nas quais nos formamos permanentemente, nos tantos 'dentrofora' das escolas. Nessas redes educativas criamos 'conhecimentossignificações', nas relações com os outros seres humanos, necessários ao nosso viver cotidiano. O que é criado passa por trocas e negociações entre diversas redes porque seus 'praticantespensantes' entram nelas e saem delas em processos permanentes e diferenciados. Por isso mesmo - ao contrário do que aprendemos/nos ensinaram por influência da corrente pedagógica que foi chamada de "Escola Nova" - não existem "muros" entre as escolas e essas outras redes. Nas escolas, as relações, ideias, 'conhecimentossignificações', crenças, artefatos culturais e tecnológicos - de que este momento é tão rico: telefones celulares, computadores, televisão etc. - produzidos em outras redes educativas estão tão presentes ou não; quer entendamos que aí não deveriam estar, mas estão - porque "encarnados" em todos os seus 'praticantespensantes'.

A utilização da narrativa, uma vez que ela é uma "[...] potência de expressão da complexidade das redes tecidas pelos sujeitos praticantes do currículo" (FERRAÇO, 2008, p. 31) e que, o tempo todo, são costuradas e entrelaçadas a falas outras, a sujeitos outros, a imagens outras, torna-se para nós indispensável em nossa pesquisa, uma vez que diversos são os personagens que preferem, ainda que de forma digital, dialogarconversar e até se fazer 'aparecer a partir das redes sociais através do Facebook e do WhatsApp.

Ao fazermos uso das narrativas, nos debruçamos sobre a forma como Alves, em sua obra, Práticas Pedagógicas em Imagens e Narrativas, relata o seu entendimento recente acerca do uso das narrativas em suas pesquisas:

[...] as narrativas (sons de todos os tipos) e as imagens como "personagens conceituais", ideia que aprendi ao ler Deleuze e Guattari (1992). Essa opção tem a ver, também, com a compreensão que partilho, depois de tantas pesquisas realizadas com os cotidianos escolares, de que narrativas e imagens indicam modos de se trabalhar nas escolas, desde sempre, em todos os seus níveis: existem muitas conversas nas escolas e muitas imagens e narrativas são 
'usadas' ${ }^{8}$ em seus processos pedagógicos, com regularidade. Por fim, esses artefatos culturais estão aqui presentes porque reconheço, e muitos concordarão comigo, que esse é um modo muito mais divertido de nos relacionarmos com os outros: quem não gosta de 'contarouvir' uma história? Quem não gosta de produzir, 'verouvirsentirpensar' e analisar imagens e sons? Com elas narrativas, imagens e sons - podemos lembrar situações/acontecimentos passados, indicar processos vividos, imaginar processos que poderiam/podem acontecer nas escolas e projetar outros no futuro. Nelas aparecem (ou nos fazem lembrar) aqueles e aquelas com quem convivemos de algum modo, em algum 'espaçotempo' e que nos deixaram marcas (ALVES, 2019, p. 21-22).

Por tratar-se de uma pesquisa utilizando dos recursos midiáticos possibilitados pelo Facebook e WhatsApp entendemos que o uso das imagens digitais que narram as vidas, também é uma produção de dados da pesquisa com os cotidianos, sendo entendidas como produções que "[...] inscrevem sentidos nos acontecimentos vividos, envolvendo, nessa produção diferentes temposespaços praticados e, ainda, diferentes fazeressaberes dos narradores praticantes" (FERRAÇO, 2016, p. 34) e ainda,“'[...] como possibilidade efetivas de visibilidade de compreensão dos acontecimentos cotidianos, a partir das expressões estéticas daqueles que vivem-praticampensam intensamente esses acontecimentos" (ALVES; FERRAÇO, 2017, p. 144).

Quando buscamos na pesquisa mais elementos/obras que consubstanciassem nosso estudo, nos submergimos nos estudos de Carvalho, ao constatar possibilidades de capturar os entrelaçamentos dos currículosformações pelo uso das imagensmovimentos. Usar estas imagens-movimentos tem a finalidade de "[...] explorar aquelas que nos inquietam porque revelam os diferentes modos de intervenção de poder que, ao lado das estratificações de saber, formam a rede de relações que constituem uma subjetividade normalizada" (CARVALHO, 2014, p. 167). Quanto a imagem, Carvalho e Roseiro (2017, p. 31-32) afirmam,

[...] a imagem é uma máquina de pensar, de pensar possibilidades de inverter o caminho habitual da vida, no caso, dos currículos praticados no cotidiano escolar, buscando renovar a existência e realizar, pelo pensamento problematizado, os tempos produzidos nas escolas, como o agenciamento do desejo de invenção dos currículos praticados no cotidiano escolar, produzindo tempos outros com novas imagens-tempo.

Inspirados pelos estudos de Deleuze e Parnet (1998, p. 73), compreendemos que "Os afetos são devires: ora eles nos enfraquecem, quando diminuem nossa potência de agir e decompõem nossas relações (tristeza), ora nos tornam mais fortes, quando aumentam nossa potência e nos fazem entrar em um indivíduo mais vasto ou superior (alegria)".

Entendemos, portanto, que a pesquisa se dá numa rede de afetos, por meio de encontrosimagens que potencializarão outras possibilidades de habitar nos cotidianos das escolas fazendo uso das tecnologias para pensar acerca das escolas e de suas múltiplas práticasteorias, por vezes, (in) capturáveis. Redes coletivas que conectadas umas às outras produzem outras possibilidades de existências e tessituras curriculares. Que ao extrapolarem a dimensão das macropolíticas, que por vezes, regulam os usos que se fazem das tecnologias, expandem-se, rizomatizam-se, e tecem uma micropolítica de resistência.

\footnotetext{
${ }^{8}$ O termo 'uso' é pensado pela autora, no grupo de pesquisa que coordena, no sentido dado por Certeau (1994): os processos desenvolvidos pelos praticantespensantes, nas redes cotidianas do viver humano, em suas relações com os artefatos culturais postos para consumo por aqueles que controlam/são proprietários do sistema de produção.
} 
Aposta-se, neste sentido, que a tessitura das redes de currículosformações, numa dimensão rizomática, estabelecem múltiplos pontos de (des)encontros e que, em cada ponto tecem novas articulações numa dimensão dos acontecimentos de afetos-afecções que tem nas imagens-movimentos das redes sociais um intercessor potente para curricular e formar. Neste sentido, mergulha-se nestes processos de fazeressaberes, de práticasteorias nas turmas de $7^{\circ}$ ao $9^{\circ}$ ano da Escola Municipal Lacerda de Aguiar, no município de Piúma-ES, afim de capturar as imagens que movimentam o pensamento e produzem uma outra forma de educação possível.

\section{Referências}

ALMEIDA, Gilvan Jorge de. Emprego do aplicativo whatsapp no ensino de química. 2015. 72f. TCC (Graduação) - Curso de Química, Instituto de Química, Universidade de Brasília, Brasília, 2015. Disponível em: http://bdm.unb.br/bitstream/10483/11240/1/2015_GilvanJorgeDeAlmeida.pdf. Acesso em: 21 mar. 2020.

ALVES, Nilda. Decifrando o pergaminho - os cotidianos das escolas nas lógicas das redes cotidianas. In: OLIVEIRA, I. B.; ALVES, N. (Org.). Pesquisas nos/dos/com os cotidianos das escolas: sobre redes de saberes. Petrópolis: DP et Alii, 2008. p. 15-38.

ALVES, Nilda (Org.). Formação de professores: pensar e fazer. 11. ed. São Paulo: Cortez, 2011.

ALVES, Nilda. Práticas pedagógicas em imagens e narrativas: memórias de processos didáticos e curriculares para pensar as escolas hoje. São Paulo: Cortez, 2019.

ALVES, Nilda; FERRAÇO, Carlos Eduardo. Pesquisas com os cotidianos em redes de conhecimento. In: AMADO, J.; CRUSOÉ, M. C. (Org.). Referenciais teóricos e metodológicos de investigação em educação e ciências sociais. Vitória da Conquista: Edições UESB, 2017. p. 129-149.

CARVALHO, Janete Magalhães. O cotidiano escolar como comunidade de afetos. Petrópolis: DP et Alii, 2009.

CARVALHO, Janete Magalhães. A problematização pelo uso de imagens-movimento e imagens-tempo na pesquisa com o cotidiano escolar. In: GARCIA, A.; OLIVEIRA, I. B. Aventuras de conhecimentos: utopias vivenciadas nas pesquisas em educação. Petrópolis, RJ: De Petrus; Rio de Janeiro, FAPERJ, 2014. p. 159-176.

CARVALHO, Janete Magalhães; ROSEIRO, Steferson Zanoni. Inventando tempos outros com os coletivos na formação docente: a potência da imagem-movimento e da imagem-tempo nas produções curriculares. In: CARVALHO, J. M. (Org.). Cinema e formação de professores $e$ currículos e... Curitiba: CRV, 2017.

CERTEAU, Michel de. A invenção do cotidiano: artes de fazer. 22. ed. Petrópolis: Vozes, 2014.

CHARAUDEAU, Patrick. Discurso das mídias. São Paulo: Contexto, 2006.

CORRÊA, Juliane. Novas Tecnologias da informação e da comunicação: novas estratégias de ensino/aprendizagem. In: COSCARELI, Carla Viana. (Org.). Novas tecnologias, novos textos, novas formas de pensar. 2. ed. Belo Horizonte: Autêntica, 2003. p. 43-50. 
DELEUZE, Gilles. Lógica do sentido. Trad. Luiz Roberto S. Fortes. São Paulo: Perspectiva, 2015.

DELEUZE, Gilles. Cinema 1 - a imagem-movimento. Trad. Stella Senra. São Paulo: 34, 2018 a.

DELEUZE, Gilles. Cinema 2 - A imagem-tempo. Trad. Eloisa A. Ribeiro. São Paulo: 34, 2018b.

DELEUZE; Gilles. GUATARRI, Félix. O que é filosofia? 3. ed. Rio de Janeiro: 34, 2010.

DELEUZE; Gilles. GUATARRI, Félix. Mil platôs: capitalismo e esquizofrenia, vol. 1. 2. reimp. São Paulo: 34, 2017.

DELEUZE. Gilles; PARNET, Clarie. Diálogos. São Paulo: Editora Escuta, 1998.

FERRAÇO, Carlos Eduardo. A pesquisa em educação no/do/com o cotidiano das escolas. In: FERRAÇO, C. E.; PEREZ, C. L. V.; OLIVEIRA, I. B. (Org.). Aprendizagens cotidianas com a pesquisa: novas reflexões em pesquisa nos/dos/com os cotidianos das escolas. Petrópolis: DP et Alii, 2008. p. 23-34.

FERRAÇO, Carlos Eduardo. ...E pesquisa com os cotidianos ou sobre imagens narrativas. In: FERRAÇO, C. E. (Org.) ...Currículos em redes. Curitiba: CRV. 2016. p. 27-40.

FERRAÇO, Carlos Eduardo; GOMES, Maria Regina Lopes. Sobre as redes que tecem práticas políticas cotidianas de currículo e formação de professores/as. Currículo sem Fronteiras. v. 13, n. 3, p. 464-477, set./dez. 2013. Disponível em: http://www.curriculosemfronteiras.org/vol13iss3articles/ferracogomes.pdf. Acesso em: 22 jul. 2018.

GARCIA, Regina Leite; ALVES, Nilda. Sobre formação de professores e professoras: questões curriculares. In: LIBÂNEO, J. C.; ALVES, N. (Org.). Temas de pedagogia: diálogos entre didática e currículo. São Paulo: Cortez, 2012. p. 489-510.

KENSKI, Vani Moreira. Tecnologias e ensino presencial e a distância. 2. ed. Campinas, SP: Papirus, 2004.

LÉVY, Pierre. As tecnologias da inteligência: o futuro do pensamento na era da informática. Trad. Carlos I. Costa. 2. ed. São Paulo: Editora 34, 2010.

LÉVY, Pierre. O que é virtual? Trad. Paulo Neves. 2. ed. São Paulo: Editora 34, 2011.

LÉVY, Pierre. Cibercultura: o futuro do pensamento na era da informática. Trad. Carlos I. Costa. 3. ed. São Paulo: Editora 34, 2018.

MORAN, José Manuel. Como transformar nossas escolas. In: MORAN, J. M. Educação 3.0 novas perspectivas para o ensino. São Leopoldo: Ed. Unisinos, 2017.

PRENSKY, Marc. Digital native, digital imigrants: digital Native imigrants - on the horizon, MCB University Press, v. 9, n. 5, p. 1-6, out. 2001.

WHATSAPP. Sobre. Disponível em: https://www.whatsapp.com/about/. Acesso em: 10 jul. 2020. 